\section{EFFECT OF LIVER SUPPLEMENT ON GROWTH OF CHILDREN}

BY

JOHN YUDKIN, M.D., Ph.D., M.R.C.P., F.R.I.C. Professor of Physiology, King's College of Household and Social Science, University of London

In the course of work on dietary reproductive factors in the rat (Wiesner and Yudkin, 1951) it was found, though not then reported, that supplements of liver caused a small but significant improvement in growth even when the animals were fed an apparently complete stock diet consisting of non-purified foods (Fig. 1). The

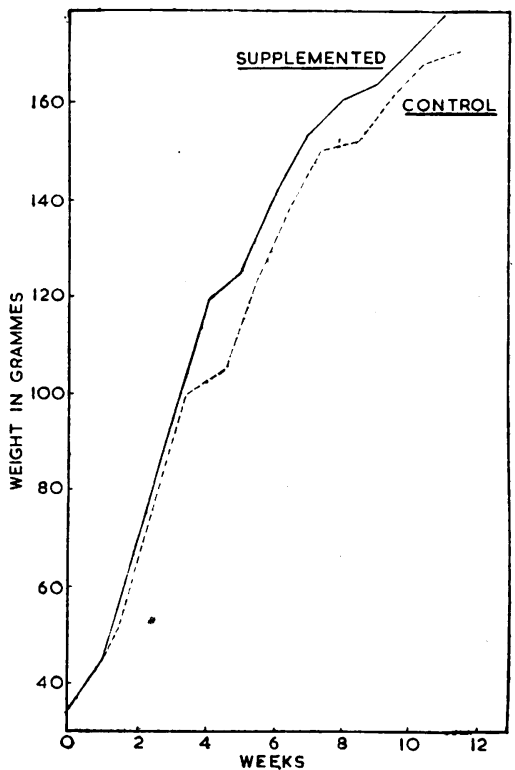

effect was produced both by fresh mammalian liver and by a specially prepared liver powder; other liver powders did not produce this promotion of growth. It was decided to test whether a similar effect on growth could be produced in children.

\section{Experimental}

Beef liver was dried in a special way under careful supervision. After establishing that it was active in promoting growth in rats, it was incorporated in to bars of chocolate with an orange flavour, so that each bar of about Fio. 1.-Effect of liver supplement on 12 female rats of strain $\mathrm{KC}$, housed individually. From weaning, rats fed ad libitum on stock diet (see Wiesner and Yudkin, 1951). Supplement consisted of 1 g. of fresh liver daily to each rat in the "liver" group.

$\frac{2}{3}$ oz. (20 g.) contained $2 \mathrm{~g}$. of liver powder (L). Bars of chocolate of the same size and flavour but of different shape and containing no liver (C) were also made for administration to children acting as controls.

The children studied were from four day nurseries in West London. All children over 2 years and under 3 years took part in the experiment ; these numbered 75 , of whom 40 were boys and 35 girls. They were all apparently well, and the average height and weight were up to standard, being, for example, slightly though not significantly greater than the figures for London children recorded by Gore and Palmer (1949). On the basis of their age, height, and weight at the beginning of the test, they were divided into two matched groups, so that about an equal number of both boys and girls at each school, of about the same age, height, and weight, fell into each group. The matron in each school was then instructed to give the children in one group chocolate " $\mathrm{L}$ " and those in the other group chocolate " $\mathrm{C}$ "; each child received one bar a day during the five days of attendance each week, so that the children in the experimental group took $2 \mathrm{~g}$. of dried liver on each school day, equivalent to $12 \mathrm{~g}$. of fresh liver. The arrangements for distributing the chocolate, either at one time or in divided amounts, differed in the different nurseries, but there was no doubt that every care was taken to ensure that each child received the type of chocolate allotted to him. The appetite of the children was apparently not affected by the chocolate.

Measurements of height to the nearest $\frac{1}{4}$ in. and weight to the nearest $\frac{1}{4} \mathrm{lb}$. were made by me with checked measuringrods and weighing machines $\left(\frac{1}{4}\right.$ in. $=0.6 \mathrm{~cm}$. ; $\frac{1}{4} \mathrm{lb} .=113 \mathrm{~g}$.). Each child, without clothes, was measured once 10 days before supplementation, once three days before supplementation, twice more during the next 10 weeks, and finally 13 weeks after the beginning of supplementation. These repeated measurements made it possible to eliminate gross errors in recording and to minimize errors in measurements. The children were examined at random, and the names and measurements recorded by a personal assistant. The group to which each child belonged was entered in the record only after the final examination.

\section{Results}

Of the 75 children with whom the experiment began, 15 left during the test, so that records of growth were available for 60 children-31 boys and 29 girls. No differences in growth between the boys and girls were evident, so that the results for both sexes have been combined.

Of the 60 children, 28 ( 14 boys and 14 girls) were in the control group and 32 (17 boys and 15 girls) in the experimental group. Because some of the children had left, the initial age, weight, and height of the control children were now on average slightly greater than those in the experimental group (Table I). The differences in height

TABLE I.-Comparison of Control and Experimental Groups. Figures Give Mean Values and Standard Errors.

\begin{tabular}{|c|c|c|c|c|c|c|}
\hline \multicolumn{2}{|l|}{ Group } & No. & $\begin{array}{c}\text { Initial } \\
\text { Age } \\
\text { (Months) }\end{array}$ & $\begin{array}{c}\text { Initial } \\
\text { Height } \\
\text { (in.) }\end{array}$ & $\begin{array}{c}\text { Initial } \\
\text { Weight } \\
\text { (lb.) }\end{array}$ & $\begin{array}{c}\text { Absence } \\
\text { Days }\end{array}$ \\
\hline Control & .. & 28 & $31 \cdot 2$ & 35.8 & $\begin{array}{c}30.7 \\
(+0.57)\end{array}$ & $\begin{array}{l}12.6 \\
(+2.08)\end{array}$ \\
\hline Experimental & .. & 32 & $\begin{array}{r}29.4 \\
( \pm 0.59)\end{array}$ & $\begin{array}{r}( \pm 5.3 \\
( \pm 0.25)\end{array}$ & $\begin{array}{r}29.9 \\
( \pm 0.55)\end{array}$ & $\begin{array}{l}13.3 \\
( \pm 1.98)\end{array}$ \\
\hline
\end{tabular}

Differences between groups not significant $(P>0.05)$.

and weight were just about those expected from the difference of nearly two months in age, although statistically the difference in age, height, or weight between the two groups was not significant. The average absences from the nurseries were almost the same for the two groups. From the absences it can be calculated that the average consumption of liver powder by the children in the experimental group amounted to $1.2 \mathrm{~g}$. daily for the 91 days (13 weeks) of the test.

After 13 weeks of supplementation appreciable and significant differences in growth were found in the two groups (Table II, Fig. 2). Compared with the control children, the

TABLE II.-Effect of Liver Supplement on Growth

\begin{tabular}{|c|c|c|c|c|c|c|}
\hline \multirow[t]{2}{*}{ Group } & & \multirow[t]{2}{*}{ No. } & \multirow{2}{*}{$\begin{array}{c}\text { Increase in } \\
\text { Height } \\
\text { (in.) }\end{array}$} & \multirow{2}{*}{$\begin{array}{l}\text { Increase in } \\
\text { Weight } \\
\text { (lb.) }\end{array}$} & \multicolumn{2}{|c|}{$\begin{array}{c}\text { No. (and \%) } \\
\text { with Gain } \\
\text { above Average }\end{array}$} \\
\hline & & & & & Height & Weight \\
\hline Control & & 28 & 0.98 & 1.64 & $11(40)$ & $10(35)$ \\
\hline Experimental & .. & 32 & $\begin{array}{c}1.20 \\
( \pm 0.050)\end{array}$ & $\begin{array}{c}2.27 \\
( \pm 0.016)\end{array}$ & $23 \quad(70)$ & $24(75)$ \\
\hline
\end{tabular}

Differences between groups significant $(P=0.01$ or less).

children receiving the liver chocolate gained 0.22 in $(0.55 \mathrm{~cm}$.) or over $20 \%$ more in height, and $0.63 \mathrm{lb}$. $(285 \mathrm{~g})$. or nearly $40 \%$ more in weight. That these results were statistically highly significant, with a probability of 1 in 100 or more against their being due to chance, was shown both by analysis of variance of the individual gains in height or weight and by the $\chi^{2}$ test applied to the number which gained more or less than the average for both groups. The effect of the liver was apparently not related to the original "nutritional status" or physique of the children, 


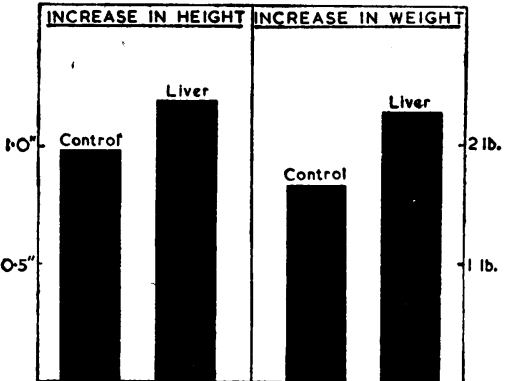

FIG. 2.-Effect of liver supplement on growth of children. for very similar gains occurred in children with either a high or a low Tuxford index (Tuxford, 1942).

\section{Discussion}

The effect of the liver preparation on growth has thus been shown to occur in children as well as in rats. In neither instance was there any reason to suppose that the unsupplemented diets were in any way deficient. It has already been mentioned that the children were apparently well and healthy.

This work recalls that of Wetzel, Fargo, Smith, and Helikson (1949) and of Chow (1951), in which oral vitamin $B_{12}$ was shown to promote the growth of children. Wetzel et al. gave $10 \mu \mathrm{g}$. daily to 11 malnourished boys and girls aged between 5 and 12 years and found that five of them showed a significant improvement in physique as measured by their progress along a "Wetzel grid." Chow studied two groups of children, the first of 45 chronically ill or malnourished children from 6 months to 12 years, and the second of 18 normal children from 18 months to 4 years. About half of the children in each group received 10 or $25 \mu \mathrm{g}$. of vitamin $\mathbf{B}_{12}$ daily. After three months for the ill or malnourished children, and six months for the normal children, there was a significantly greater gain in weight in those receiving the vitamin.

The work of these authors differs in three respects from that described in this paper. First, their groups were both smaller and much less homogeneous as regards age, weight, and height. Chow himself stresses that "owing to the heterogeneity of the subjects with chronic illness and the small numbers of the normal children studied, the results are merely considered suggestive of trends." Not only was the present study made on 60 children, but the narrow range of age, and the distribution according to sex, height, and weight, ensured that our subjects were more homogeneous and the groups better matched.

Secondly, apart from the small group of 18 normal children studied by Chow, both he and Wetzel et al. were dealing with ill and malnourished children. The children of the present study were apparently well, and in particular there seemed to be no relation between improvement in growth and the "nutritional state" of the children as measured, for example, by the Tuxford index.

The third difference between this work and that of the other investigators is in the nature of the supplement. It is of course tempting to suppose that the liver produced its effect because of its content of vitamin $B_{12}$. However, there are several indications that this was not so. (1) Vitamin $B_{12}$ does not always produce an increase in growth in children, for Downing (1950) has reported that it does not stimulate the growth of premature infants. More recently, Benjamin and Pirrie (1952) have not been able to confirm the results of Wetzel et al. and of Chow on chronically ill children. (2) Microbiological assay has shown that our liver powder contained rather less than $1 \mu \mathrm{g}$. of vitamin $\mathbf{B}_{12}$ per g. Although there is evidence that the availability of the vitamin from liver is not the same for micro-organisms as it is for human beings, it is unlikely that the average amount of $1.2 \mathrm{~g}$. of liver powder daily supplied anything approaching the 10 to $25 \mu \mathrm{g}$. given by the American workers. (3) A preparation of fish liver known to be an active source of vitamin $B_{12}$ was not active in promoting the growth of rats on the stock diet. (4) Continued (unpublished) experiments with rats have shown that, unlike liver, vitamin $B_{12}$ added to the stock diet does not produce an increase in growth.
It would seem probable, therefore, that the factor responsible for the effect on growth is not vitamin $B_{12}$. It should also" perhaps be added that the growth factor is likely to prove different from " reproductive factor $R$," since the preparation of fish liver which did not promote growth was nevertheless a potent source of "factor $R$ " (Wiesner and Yudkin, 1951).

Work is being continued to determine the distribution and nature of the growth factor. Until further information is available it cannot be assumed that the factor is present in all preparations of liver. This report is nevertheless presented at this stage, since it seems sufficiently interesting that liver contains what appears to be a new nutritional factor, which produces such a significant effect on the gain in height and weight of children in such a short time.

\section{Summary}

Experiments with rats showed that growth was significantly improved when a powdered preparation of liver was added to a supposedly complete stock diet. A similar preparation was given to apparently normal children of 2 years of age, at the average rate of $1.2 \mathrm{~g}$. a day. After 13 weeks the 32 children taking this supplement gained on average about $\frac{1}{4}$ in. $(0.6 \mathrm{~cm}$.) more in height and $10 \mathrm{oz}$. $(285 \mathrm{~g}$.) more in weight than the 28 control children. These gains were roughly $20 \%$ and $40 \%$ more than those of the control children. Reasons are given for the belief that the dietary factor responsible for this improved growth was not vitamin $\mathrm{B}_{12}$.

I am indebted to Messrs. Kylon Ltd. for the special preparation of liver powder (Kylon G.F.), to Messrs. Cadbury Bros. Ltd. and their chief chemist, Mr. R. V. Wadsworth, for the manufacture and supply of the chocolate, and to Dr. W. F. J. Cuthbertson, of Glaxo Laboratories, for the assays of vitamin $B_{12}$. I am especially grateful for the help and co-operation of Sir Allen Daley (lately Medical Officer of Health, L.C.C.), Dr. V. Russell (Divisional Medical Officer, L.C.C.), and the matrons and their colleagues at the four day nurseries.

\section{REFERENCES}

Benjamin, B., and Pirrie, G. D. (1952). Lancet, 1, $264 ;$ Med. Offr, 87, 137.

Chow, B. F. (1951), J. Nutrit., 43, 323.

Downing, D. F. (1950). Sclence, 112, 181.

Gore, A. T., and Palmer, W. T. (1949). Lancet, 1, 385.

Tuxford, A. W. (1942). J. Hyg., Camb., 42, 549.

Wetzel, N C., Fargo, W. C., Smith, I. H., and Helikson, J. (1949). Science, 110, 651 .

Wiesner, B. P., and Yudkin, J. (1951). Nature, Lond., 167, 979.

H. Kalmus, H. L. Nixon, and C. R. Ribbands read a paper to the Royal Society on June 19 on the origin of the odours by which honeybees distinguish their companions and the division of labour and food transmission within the honeybee community. During her lifetime every honeybee performs a sequence of tasks, the oldest bees being foragers. Most bees omit some of the earlier duties and tasks are allocated in accorfance with the needs of the colony. These needs are determined by food supplies and appreciated through food transmission. Widespread food transmission or food sharing was demonstrated by a tracer technique. All the major tasks involve the manipulation of food, and through food transmission all the bees performing any task are evenly fed. Any surplus causes the older members to leave their group and join another. Experiments proved that foraging bees recognize their hivemates by their odour, which they distinguish from the odour of other honeybees. The common colony odour is derived from the food transmission, which provides an identical diet with identical odorous waste products. Food transmission is therefore the most primitive and the most important method of communication of the honeybee community. 